\title{
The Effects of Processing Instruction and Traditional Instruction on Iranian EFL Learners' Writing Ability
}

\author{
Hossein Hashemnezhad ${ }^{1} \&$ Sanaz Khalili Zangalani ${ }^{1}$ \\ ${ }^{1}$ Department of Foreign Languages and Literature, Tabriz Branch, Islamic Azad University, Tabriz, Iran \\ Correspondence: Sanaz Khalili Zangalani, Department of Foreign Languages and Literature, Tabriz Branch, \\ Islamic Azad University, Tabriz, Iran. E-mail: sanaz.mp@gmail.com
}

$\begin{array}{ll}\text { Received: August 21, } 2012 & \text { Accepted: September 10, } 2012 \quad \text { Online Published: September 14, } 2012 \\ \text { doi:10.5539/elt.v5n11p125 } & \text { URL: http://dx.doi.org/10.5539/elt.v5n11p125 }\end{array}$

\begin{abstract}
The aim of the present paper was to investigate the effects of processing instruction and traditional instruction on Iranian EFL learners' writing ability. Thirty participants who were non-randomly selected out of 63 Intermediate EFL learners, taking English courses in a language institute in Khoy-Iran, participated in this quasi-experimental study. All the participants were female with the age range of 18-24. The participants were randomly assigned into two experimental groups of processing instruction and traditional instruction. Two different instructional packages were used as treatment and two free writing tasks were employed as pre-test and post-test in this study. The results revealed that although both instructions had positive effects on Iranian EFL learners' writing ability, processing instruction group performed significantly better than traditional instruction. Some pedagogical implications of the findings were presented. The results might be helpful in syllabus design and teaching methodology.
\end{abstract}

Keywords: processing instruction, traditional instruction, grammar instruction, EFL writing

\section{Introduction}

\subsection{Background}

As Ellis (2001) maintains, the model of language acquisition that informs mainstream Second Language Acquisition (SLA) identifies three main processes: intake, acquisition, and language production. Traditionally, language instruction has been aimed at the last of these processes, that is, teachers combine some sort of explicit grammar instruction with activities that concentrate on providing learners with opportunities to produce the target structure (Erlam, 2003a). However, VanPatten and Cadierno (1993) argue that instead of trying to change how learners produce language output, instruction should focus on altering how learners process input. They claim that instruction that changes the way input is perceived and processed by the learner is more likely to become intake and thus have an impact on the developing language system.

Processing Instruction (PI), as an explicit Form-Focused Instruction (FFI), is a pedagogical language instruction developed and revised by VanPatten (1996, 2002a, 2004a). VanPatten (2004a) believes that the aim of PI is to engage learners in activities which have been manipulated to make language forms more salient so that learners move toward more systematic processing tools in order to acquire those forms more efficiently and successfully. In PI students are given explicit information about this processing strategy and the correct target language strategy. They are also given meaning-focused input-based activities, called Structured Input activities that direct them away from production. They do not engage in production of the target structure.

Traditional grammar Instruction (TI), another type of explicit FFI, is defined by VanPatten (2000) as "explanation plus output practices that move learners from mechanical to communicative drills" (p. 54). That is to say, TI involves explanation and output practice of a grammatical point and focuses on the manipulation of learner output to affect change in the developing system.

\subsection{Significance of the Study}

As opposed to TI, the purpose of PI is to change the way that learners attend and process input, considering that acquisition is an input-dependent process and takes place when learners are exposed to meaning-bearing input (VanPatten, 1996). As outlined by Wong (2004), PI "pushes learners to abandon their inefficient processing strategies for more optimal ones so that better form-meaning connections are made" (p. 35). 
Research has demonstrated that in evaluations of EFL learner writing, grammatical accuracy plays an important role (Hinkel, 2002). The presence of grammar errors has a negative impact on the native speaker perceptions of the quality of L2 writing (Johns, 1997; Johnson \& Roen, 1989, all cited in Hinkel, 2002).

Despite the crucial changes have been done, the question unanswered here is that: how grammar should be taught in EFL classes? More specifically, what is the most proper way of grammar instruction for EFL learners to improve their writing ability? Therefore, finding the proper approach of grammar instruction, as an alternative to traditional approaches, to improve EFL learners' writing ability has an important place within the scope of SLA. Comparing the efficiency of PI and TI on writing ability of Iranian EFL learners can be a challenge to find better alternatives for teaching grammar in EFL classes.

\section{Review of the Related Literature}

The role of grammatical instruction in SLA has long been questioned. As Rutherford (1987, cited in Celce-Murcia, 1991) points out, for 2500 years the teaching of grammar had often been synonymous with foreign language teaching. The role of grammar instruction has, however, generated a great debate in L2 teaching for more than 40 years (Ellis, 2001). During the past decades grammar has moved from a position of central importance in language teaching to pariah status, and back to a position of renewed importance (Celce-Murcia, 1991).

Saraceni (2008) asserts that although it seems that the role of grammar instruction in SLA was decreasing with the rise of communicative methodologies in the late 1970s, its place in SLA still continues to be discussed. Over the recent decades the developments about grammar instruction has been highly questioned due to consistent succession of new language acquisition methods. Therefore, grammar instruction innovations are in the center of innovations in SLA methodology.

\subsection{Processing Instruction (PI)}

PI model, proposed by VanPatten (1996), has been widely referenced in most input processing studies. Wong and VanPatten (2003) suggest three basic features for PI. These are as follows:

1) Learners are given information about a linguistic structure or form.

2) Learners are informed about a particular input processing strategy that may negatively affect their picking up the form/structure during comprehension.

3) Learners are pushed to process the form/structure during activities with structured input - input that is manipulated in particular ways so that learners become dependent on form and structure to get meaning, and/or to privilege the form/structure in the input so that learners have a better chance of attending to it. Learners do not produce the structure or form during structured input activities.

As can be understood from what mentioned above, the PI approach is designed to avoid specific problems that learners have in processing input. In order to have a clearer understanding of the PI, we should introduce TI and the difference between the TI and PI.

\subsection{Traditional Instruction (TI) vs. Processing Instruction}

TI involves explanation and output practice of a grammatical point and, according to VanPatten and Cadierno(1993), focuses on manipulation of learner output. That is, instruction occurs by explaining a grammatical concept and then having learners practice producing a given structure or form (Figure 1).

$$
\begin{aligned}
& \text { INPUT } \stackrel{\text { I }}{\rightarrow} \text { INTAKE } \stackrel{\text { II }}{\rightarrow} \text { DEVELOPING SYSTEM } \stackrel{\text { III }}{\rightarrow} \text { OUTPUT } \\
& \text { FOCUSED PRACTICE }
\end{aligned}
$$

Figure 1. Traditional Grammar Instruction in Foreign language Teaching (VanPatten and Cadierno, 1993)

As outlined by Wong (2004), PI (Figure 2), however, "pushes learners to abandon their inefficient processing strategies for more optimal ones so that better form-meaning connections are made" (p. 35). 


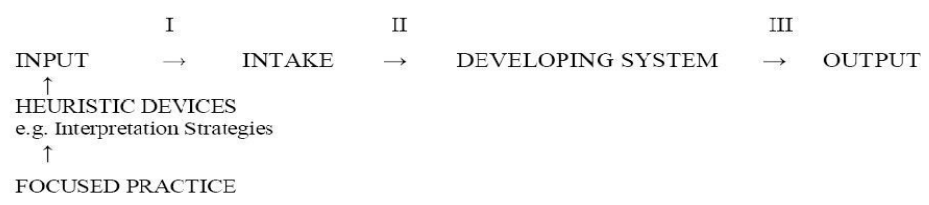

Figure 2. Processing Instruction in Foreign Language Teaching (VanPatten and Cadierno, 1993)

As can be depicted from the figures above, PI attempts to change the strategies and mechanisms used by language learners when processing L2 input; whereas TI involves presenting learners with explanations regarding the form and then giving them practice in how to make sentences with the relevant grammar point.

Although VanPatten (2002a) recently asserted that "output may play a number of important roles in language development" (p. 762) and that, in fact, it plays a facilitative role in acquisition (VanPatten, 2004a), he did not agree with the claim that "using a form in one's output is a direct path to acquisition" (VanPatten, 2004a, p. 27) and suggested instead, on the basis of current evidence, that acquisition does not appear to be dependent on output (VanPatten, 2004a). VanPatten (1993, 1996, 2000) proposes that PI has an effect on changing L2 learners' underlying developing system so as to effect changes in their output, and that this effect cannot be achieved by any type of output-based instruction.

Sharwood Smith (1993) regards that PI does not aim at raising learners' consciousness about grammatical form. That is to say, the ultimate scope of PI, according to Benati (2001), is not about raising consciousness awareness about a grammatical form, instead, to make the learner appreciate the communicative function of a particular form and consequently enrich the learner's intake.

\subsection{Structured Input (SI) Activities}

One of the criticisms that VanPatten (1996) makes of many teaching materials is that learners can do many activities without understanding the content. However, this is not acceptable within the PI model. In PI, learners process input to understand it and some activities are designed to focus their attention on getting the right meaning from the stimuli (VanPatten, 1996). The activities used in PI are called 'Structured Input activities' (SI). The term 'Input' is used because learners actively focus on processing input instead of producing language as output. The term 'Structured' is used since the input is not spontaneous.

\subsubsection{Refrential Activities vs. Affective Activities}

VanPatten (1993) distinguishes between referential and affective activities as two different types of SI activities. Referential activities are those for which there is a right or wrong answer and for which the learner must rely on the targeted grammatical form to get meaning. Affective activities are those in which learners express an opinion, belief, or some other affective response and are engaged in processing information about the real world. Normally, as Wong and VanPatten (2003) indicate, a sequence of SI activities would begin with two or three referential activities. Following referential activities, learners are engaged in affective SI activities.

\subsection{Related Empirical Studies on PI and TI}

VanPatten and Cadierno (1993) did the first research study to investigate the effects of PI on SLA. They compared PI to TI, for effectiveness in acquisition of Spanish direct object pronouns by second year university students. The TI group received a presentation of the form, followed by practice production activities which moved from mechanical drills to meaningful activities to more communicative practice. The PI group started with a comparison of subject and object pronouns, with attention drawn to position. The treatment was followed by referential activities, and affective activities in which students gave opinion responses utterances. None of the referential and affective activities involved production of the forms. The effects of these two types of instruction were measured by interpretation and production posttest tasks. On the interpretation tasks, only the PI group demonstrated gains. On the production tasks both groups outperformed the control group, with no significant difference between the two treatment groups. VanPatten and Cadierno (1993) concluded that TI did not impact the developing system directly, but resulted "in a different knowledge system", while PI altered "the way in which the subjects processed input, which in turn had an effect on the developing system" (p. 53).

Following VanPatten \& Cadierno (1993), several PI studies have been conducted in order to compare the relative effects of PI and TI. Cadierno (1995) researched the effects of PI on the acquisition of the Spanish past tense. There were three groups of participants: A control group that received no instruction, a treatment group that 
received TI which was production-based, and a treatment group that received PI. The results of this study revealed that PI group performed better than the other two groups on both comprehension and production tests. Her conclusion was that PI once again proved to yield better results than TI.

Benati (2001) compared PI, TI and a control group using the Italian future tense as the target form. The study included a pre-test, an immediate post-test, and a three week delayed test. The test was made up of an interpretation task, a written sentence-level task, and an oral task. On the interpretation, the PI group improved significantly better than the TI group and the control group did not show any improvement. The production test results revealed that PI and TI groups equally improved while the control group did not.

Allen (2000) investigated the relative effect of PI and TI on the acquisition of the French causative and found that PI was as effective as TI enabling learners to interpret the French causative and that TI is more effective in enabling learners to produce the French causative. VanPatten and Wong (2004) replicated Allen's (2000) study and found different results from her study but similar results VanPatten \& Cadierno study (1993). They looked at the effects of PI vs. TI focusing on the acquisition of learners' ability to improve and interpret the French causative. In this study, on the interpretation task PI group was superior to TI group. On the production task, there was no significant difference between PI and TI groups. Both groups were superior to the control group.

Buck's (2006) research also produced results which confirm VanPatten and Cadierno's (1993) research. In her study Both PI and TI groups demonstrated improvement on the first interpretation posttest, but the PI group's performance was significantly better. By the third posttest only the PI group performed better than the control group. On the production test, both treatment groups performed better than the control group with no significant difference between them, but the PI groups score was superior in the third posttest. Again, PI is thought to have changed how learners process input and thereby contributed to restructuring their linguistic system.

From the studies reviewed, it seems clear that PI is superior to mechanical output practice for acquisition (VanPatten \& Cadierno, 1993; Cadierno, 1995; Allen, 2000; Benati, 2001; Buck, 2006). As VanPatten (1993) says, it apparently delivers a "double bonus: better processing of input and knowledge that is apparently also available for production" (p. 54).

\section{Objectives of the Study}

Since VanPatten launched a research agenda centered on PI (VanPatten \& Cadierno, 1993), it has been researched from a variety of angles, spawning some dozen empirical studies in a variety of languages. Although, the efficiency of PI has been significantly consistent in learners' ability to produce restricted stream of target language, that is, at sentence level, no research has done to examine the efficiency of PI and TI types of explicit grammar instruction on writing ability of EFL learners. The present study was an attempt to find the best alternative of explicit grammar instruction to boost the EFL learners' writing ability. The study also contributed in the ongoing debate as to the best method of explicit grammar instruction by comparing the effectiveness of the of PI and TI in improving learners' writing ability.

The results of this study will enable researchers to see whether or not PI and TI have beneficial effects on learners' developing system with regard to their EFL writing ability. This study also bears significance as it is the very first study that has been undertaken in an EFL context where the relative effects of two instructional interventions under investigation on EFL learners' writing ability have never been studied. This study, in this sense, has been expected to make an important contribution to implications of grammar instruction and writing in EFL setting. The present study also shed light on the continuing debate of efficacy of PI versus TI.

To achieve this aim, the present study employed a quasi-experimental design with two experimental groups each of which receive a different type of treatment corresponding to PI and TI forms of explicit instruction. The study used a pretest-posttest design to compare the learners' progress after the application of two different types of instruction. For analyzing the data obtained from the experiment, descriptive and inferential statistics were used.

\subsection{Research Questions and Hypotheses}

The motive behind this research was to find out which kind of explicit grammar instruction is more effective to improve Iranian EFL learners' writing ability. To this end, the research questions that were specifically investigated in this study were the followings:

1. Does PI have a positive effect on EFL learners' writing ability?

2. Does TI have a positive effect on EFL learners' writing ability?

3. Is there any difference between the effects of PI and TI on EFL learners' writing ability?

Accordingly the following four research hypotheses are developed: 
1. PI has an effect on EFL learners' writing ability.

2. TI has an effect on EFL learners' writing ability.

3. There are differences between the effects of PI and TI on EFL learners' writing ability.

\section{Method}

\subsection{Participants}

The participants of the present study were studying English in a language center in Khoy, Iran. Thirty participants, out of 63 intermediate level participants, were non-randomly selected through purposive sampling technique for the present study. None-random selection of thirty participants was due to homogenize the age range, educational and cultural background of the learners. Then, the participants were randomly assigned to two groups of 15 through simple random sampling: PI and TI. The participants were all adults with the age range of 18-24. All the participants were female and came from a bilingual background, i.e. Turkish and Persian. They were native speakers of Turkish whose second language was Persian.

\subsection{Instrumentation}

The instruments of the study were as follows:

\subsubsection{Treatment Packages}

Two different treatment packages were developed for the present study. Each package was designed to reflect a different approach to the acquisition of target structures- simple present, present continuous, present perfect, simple past, past continuous, and past perfect. The first package was PI package and the second was TI package. Each of these packages includes two sections. Section 1 of these packages includes explicit information on the target structures and section 2 includes some exercises of those target structures, representative of each instruction.

\subsubsection{Rating Scale}

For rating the pre-test and post-test of the learners Tanko's (2005) analytic writing scale, developed by the Hungarian School-leaving English Examination Reform Project, was used. The learners' performance was assessed on the basis of grammar criteria, using an 8-level scale (bands from 0 to 7).

\subsubsection{Assessment Tasks}

Two free writing tasks were used to collect data from the participants. A free writing task was used for pre-test to evaluate the primary ability of the learners in writing skill, and another free writing task were used as post-test. The later one required the learners to demonstrate their ability to implement the knowledge of the target structures in language use. These free writing tasks were about daily life and the life in the past to increase the probability of the use of past and present tenses in English context.

\subsection{Procedure}

In this study, thirty-two participants out of sixty-three intermediate EFL learners were selected non-randomly for this study. First, thirty-two participants were given a pretest consisting of a free writing task to determine whether the possible effects to come from the treatments were due to the treatments themselves or some prior knowledge was leading to any positive results. Those who performed seventy percent or above on the pre-test (2 participants) were eliminated from the data pool. Then, thirty participants were non-randomly assigned to three groups of PI and TI to receive two different instructions.

Two weeks after the pretest administered to the groups, the treatment groups of PI and TI received two complete hours of instruction of target structures. Two different instruction packages were used in this study. Each of these packages included two sections. Section 1 of the packages consisted of explicit information on each tense, which was the same in all three instruction types. PI package included some more strategies and notifications which were to help the learners be more aware about the ways tenses used in English. TI package did not include these strategies. It was primarily based on mechanical learning.

Section 2 of the packages consisted of exercises which required the learners to employ what they have already learned from the instructional section. PI instructional package included SI activities. SI activities themselves consisted of some recognition tasks (referential activities) plus contextualized communicative tasks (affective activities). TI package included some mechanical drills and then communicative tasks.

PI instructional group received explicit instruction of the target structures. The learners, first of all, were given some explicit information about where and when the target structures are used. Then they were given some 
strategies and notifications to be aware of the problems they may encounter while recognition of tenses.

After explicit instruction was given about the target forms, participants were engaged in SI activities. In total three activities were designed for each tense. Two of them were referential and one of them was affective. Referential activities required participants to find the correct answer out of possible other alternatives and affective activities were based on participants' opinions or ideas about a subject specific to the activity. Activities used all written stimuli. It should be noted here that the production of the target structures were neither targeted nor included in any of the SI activities. Vocabulary used in the activities was appropriate for the participants' level of English.

TI group received only explicit instruction of the target structures. The learners were just given some explicit information about where and when the target structures are used. They were not given any strategies or notifications to be aware of the problems they may encounter while recognition of tenses.

After the presentation of explicit information on the target forms, TI group was engaged in traditional activities. In total two activities were designed for each tense. One of them was mechanical drill and the other one was communicative task. Mechanical drills required the participants to change the verbs in the parentheses into the target form mechanically, without paying attention to the meaning of statements. Communicative tasks were based on the participants' experiences, thoughts, or beliefs and the content of the responses were up to the participants but the structure that they were supposed to use was the targeted tense in each task.

Another free writing task as a post-test, which was a different version of the pre-test, was given to all participants of both groups right after the instruction to assess and compare the effectiveness of two different types of explicit instruction on the acquisition of target structures. Both pre-test and post-test writings were rated based on Tanko's (2005) writing scale. According to this scale, the essays were rated out of seven. Raw scores from the pretest and posttest, obtained based on Tanko's (2005), were submitted to a series of ANOVAs.

\section{Data Analysis and Results}

This study was an attempt to find the evidence to accept or reject three research hypotheses stated earlier. Therefore, after exposing experimental treatments to each group, the researchers analyzed the results of the study by means of descriptive statistics and inferential statistics. To this end, first, the significant differences between pretest and posttest scores of PI and TI were measured.

\subsection{Descriptive Statistics for PI and TI Groups}

Table 1 shows the descriptive statistics for pre-test and post-test of PI and TI groups including the frequency, mean, mode, standard deviation, and minimum and maximum scores.

Table 1. Descriptive Statistics Index for Pre-test and Post-test of PI and TI

\begin{tabular}{lcccccc}
\hline & $\mathrm{N}$ & Mean & Mode & Std. Deviation & Minimum & Maximum \\
\hline PI Pre & 15 & 3.2667 & 3.00 & .59362 & 2.00 & 4.00 \\
PI Post & 15 & 5.3333 & 6.00 & .81650 & 4.00 & 6.00 \\
TI Pre & 15 & 3.0667 & 3.00 & .79881 & 2.00 & 4.00 \\
TI Post & 15 & 4.1333 & 4.00 & .83381 & 3.00 & 6.00 \\
\hline
\end{tabular}

The difference between all descriptive statistics of pre-tests and post-tests of each group is illustrated in Table 1. Considering Table 1, while, the mode (the most frequently obtained score), in PI pre-test and post-test are 3.00 and 6.00, respectively, in TI pre-test and post-test are 3.00 and 4.00. Minimum score is 2.00 and belongs to both pre-test groups and maximum score is 6.00 and belongs to, again, both post-test groups.

\subsection{Normal Distribution Assumption Testing}

In order to investigate the normality assumption of the distributed scores of the tests in two groups, the researchers used the One-Sample Kolmogorov-Smirnov Test. 
Table 2. The Result of One-Sample Kolmogorov-Smirnov Test PI and TI Groups in pre-test and post-test Administrations

\begin{tabular}{lcccccccc}
\hline \multicolumn{7}{c}{ Normal Parameters ${ }^{\mathrm{a}, \mathrm{b}}$} & \multicolumn{5}{c}{ Most Extereme Differences } \\
\hline & & Mean & Std. Deviation & Absolute & Positive & Negative & $\begin{array}{c}\text { Kolmogorov- } \\
\text { Smirnov Z }\end{array}$ & $\begin{array}{c}\text { Asymp.Sig. } \\
\text { (2-tailed) }\end{array}$ \\
\hline PI pre & 15 & 3.2667 & .59362 & .340 & .340 & -.260 & 1.317 & .062 \\
PI post & 15 & 5.3333 & .81650 & .326 & .207 & -.326 & 1.263 & .082 \\
TI pre & 15 & 3.0667 & .79881 & .212 & .200 & -.212 & .821 & .510 \\
TI post & 15 & 4.1333 & .83381 & .297 & .297 & -.236 & 1.150 & .142 \\
\hline
\end{tabular}

Table 2 illustrates that there are not any significant differences between the scores of each group. The significance levels of both pretest and posttest scores of both PI and TI groups are higher than 0.05 (sig. for all groups are respectively $=.062, .082, .510, .1420 .05$ ). As the scores of the tests and error numbers in both groups are normally distributed, the researcher is allowed to use One-Way ANOVA Test for analyzing the data.

\subsection{Statistical Analysis of PI and TI groups}

\subsubsection{Investigating Hypothesis 1}

Hypothesis 1: PI has an effect on EFL learners' writing ability.

Or statistically:

There is a significant difference between the Mean of pre-test and post-test scores of PI group.

Paired Samples Test used for comparing the Means of pre-test and post-test of PI are illustrated in Table 3.

Table 3. Paired Samples Test of PI Group's Pre-test and Post-test Means

\begin{tabular}{|c|c|c|c|c|c|c|}
\hline & Mean & Std. Deviation & Std. Error Mean & $\mathrm{T}$ & $\mathrm{df}$ & Sig. (2-tailed) \\
\hline \multicolumn{7}{|c|}{ PI pre } \\
\hline Pair & -2.45638 & .70373 & .18170 & -11.374 & 14 & .000 \\
\hline \multicolumn{7}{|c|}{ PI post } \\
\hline
\end{tabular}

The Mean of pre-test is $\mathrm{M}=3.27$, the Mean of post-test scores is $\mathrm{M}=5.33$, and the standard deviation of them are $\mathrm{SD}=0.59$ and $\mathrm{SD}=0.82$, respectively (Table 1 ). The amount of $t$ is calculated, according to Table 3 , and $t=11.374$, with $d f=14$, and it is significant (sig=0.000<0.05) at 0.05 level. Therefore, the hypothesis 1 is accepted and it can be concluded that there is a significant difference between the Means of pre-test and post-test scores in PI group, with $99 \%$ certainty. That is, PI has a significant effect on EFL learners' writing ability improvement.

5.3.2 Investigating Hypothesis 2

Hypothesis 2: TI has an effect on EFL learners' writing ability.

Or statistically:

There is a significant difference between the Mean of pre-test and post-test scores of TI group.

Paired Samples Test is used for comparing the Means of pre-test and post-test of TI too (Table 4).

Table 4. Paired Samples Test of TI Group's Pre-test and Post-test Means

\begin{tabular}{|c|c|c|c|c|c|c|}
\hline & Mean & Std. Deviation & Std. Error Mean & $\mathrm{T}$ & $\mathrm{df}$ & Sig. (2-tailed) \\
\hline \multirow{3}{*}{ Pair } & TI pre & & & & & \\
\hline & -1.06667 & .70373 & .18170 & -5.870 & 14 & .000 \\
\hline & TI post & & & & & \\
\hline
\end{tabular}


The Mean of pre-test, considering Table 1, is $\mathrm{M}=3.07$,the Mean of post-test scores is $\mathrm{M}=4.13$, and the standard deviation of them are $\mathrm{SD}=0.80 \mathrm{SD}=0.83$, respectively. The amount of $t$ is calculated, according to Table 4 , and $t=5.87$, with $d f=14$, and it is significant $(s i g=0.000<0.05)$ at 0.05 level. Therefore, the hypothesis 2 is accepted and it can be concluded that there is a significant difference between the Means of pre-test and post-test scores in TI group, with $99 \%$ certainty. That is to say, TI has a significant effect on EFL learners' writing ability improvement.

\subsubsection{Investigating Hypothesis 3}

Hypothesis 3: There are differences between the effects off PI and TI on EFL learners' writing ability.

Or statistically:

There are significant differences between post-test mean scores of PI and TI.

In this kind of statistics a comparison is made between means of the two groups in the pretest and the posttest. The two groups' scores in the pretest were subject to an independent- samples $t$-test.

Table 5. Paired Samples Test of PI and TI Pre-test Scores

\begin{tabular}{lccccccc}
\hline & & Mean & Std. Deviation & Std. Error Mean & T & df & Sig. (2-tailed) \\
\hline \multirow{2}{*}{ Pair 1 } & PI pre & & & & & & \\
& & .20000 & .94112 & .24300 & .823 & 14 & .424 \\
& TI pre & & & & & & \\
\hline
\end{tabular}

According to Table 5, the result showed that as the significance level of t-test was Sig $=0.424>0.05$, there were no significant differences between the two groups' pre-test score means. This means that the two groups were equivalent in terms of their pre-test and any differences in the posttest results could only be attributed to the differences in type of instruction.

In order to investigate the validity of hypothesis 3, an independent Paired-samples t-test was conducted on the two groups' pose-test scores.

Table 6. Paired Samples Test of PI and TI Post-test Scores

\begin{tabular}{|c|c|c|c|c|c|c|c|}
\hline & & Mean & Std. Deviation & Std. Error Mean & $\mathrm{T}$ & $\mathrm{df}$ & Sig. (2-tailed) \\
\hline & & & & & & & \\
\hline \multirow[t]{2}{*}{ Pair } & 1 & 1.20000 & 1.32017 & .34087 & 3.520 & 14 & .003 \\
\hline & & & & & & & \\
\hline
\end{tabular}

As illustrated in Table 6, the results of this test showed significant difference between the two groups' post-test score means, $\mathrm{Sig}=0.003<0.05$. This meant that hypothesis 3 is accepted and the difference between the effects of PI and TI on EFL learners' writing ability was significant.

\section{Discussion}

The present study looked at the effects of PI and TI on Iranian EFL learners' writing ability and whether these two instructions result in differential effects. Two free writing tasks were administered as a pre-test and a post-test. The purpose of the pr-tests was to ensure the homogeneity of participants of two groups before treatment. The purpose of the post-tests was to measure the learners' gains in performance immediately after three different instruction types. The results gained through two different treatments are to be interpreted based on hypotheses of the present study.

Research hypotheses 1 and 2 of the present study stated that PI and TI would bring about improved performance on writing of Iranian EFL learners. The results of statistics confirmed hypotheses 1 and 2 and showed that both groups performed significantly better in their post-tests, and therefore, it can be indicated that both of instructions were effective in improvement of EFL learners' writing ability, in general.

Research hypothesis 3 stated that there would be a significant difference between the effects of PI and TI on EFL 
learners' writing ability. By comparing the post-test mean scores of two groups, PI group seemed to perform significantly better than TI group.

This study, first confirms Norris and Ortega (2000) ideas of using explicit instruction. The results obtained from this study were supportive of using explicit grammar instruction types (such as PI andTI) in EFL context, especially the use of PI in EFL classrooms to enhance the learners' grammatical knowledge and their ability in written production at discourse level.

The results of the PI group lend support to VanPatten's (1996, 2002, 2004a) model of second language input processing. PI seems to affect the developing system via intake and this system, in turn, enables the learner to produce linguistic forms under certain circumstances. Moreover, the results of this study emphasize the important role of input in second language acquisition. Through PI, the implication that grammar instruction should be tied to input has gained importance (VanPatten, 2003). The researcher in this study indicates the effectiveness of PI on EFL learners' writing ability.

The findings of this study support the results of a significant amount of research which has supported the efficacy of PI (e.g. Benati, 2001; Farley, 2001; VanPatten \& Cadierno, 1993). In addition to offering evidence as to the effectiveness of PI, some researchers have made claims that PI directly affects the acquisition of target forms, whereas TI results in learned linguistic knowledge (VanPatten \& Cadierno, 1993).

The results of the study reject the idea that TI can be as effective as PI when it is matched to PI on all variables other than practice mode. Recent studies by Benati (2005) and Farley (2001) have examined this question. Insofar there was no difference between groups on production measures.

In sum, the results of this study confirm Farley (2001) that indicates that PI has an overall greater effect on how learners interpret and produce the target structures. It seems that PI has a beneficial effect on the way in which the learners processed the input, and this leads to some type of internalization in their developing system that leads to improvement in production as well.

\section{Conclusion}

In the light of findings in the present study, the positive effects of PI and TI on EFL learners' writing ability were demonstrated. The findings revealed that although both types of instructions showed a positive improvement in writing ability of intermediate EFL learners, the effects of PI was more evident than TI.

The findings of the present study bring about some pedagogical implications for EFL curriculum developers and teachers, and learners. Given the benefits that PI brought about in the present study, the instruction type might be incorporated into a curriculum. In curriculum development based on PI, it is certain that PI requires a structural syllabus taught by means of SI activities. Through PI, the implication that grammar instruction should be tied to input has gained importance (VanPatten, 2004a). PI is entirely input-based and the SI activities can be presented in both written and oral form.

The findings of the present study may provide EFL teachers with invaluable insights as to the selection of the best and the most effective techniques to put across the target grammatical features of the L2. The study shows that focusing learners' attention on the formal characteristics of the target structures facilitates the rate of EFL learning. Apart from that, the present study points out that explicit grammar instruction is beneficial in making the learners in the instructional groups notice the target structures' recognition and use in L2.

The researcher in the present study indicated consistent priority of PI over TI. However, there are many questions regarding PI that remain unanswered and call for further research. Some changes in the assessment measures used in research investigating PI might result in different results and help answer questions that have been raised by PI critics. In several studies, comprehension or interpretation results are higher for groups receiving input-based treatment or production results are higher for output-based treatment groups on immediate posttests (Qin, 2008; Morgan-Short \& Bowden, 2006; Erlam, 2003a). In order to address whether skill development is affecting the results, assessment measures which differ substantially from treatment activities should be devised.

\section{References}

Allen, L. Q. (2000). Form-meaning connections and the French causative: An experiment in processing instruction. Studies in Second Language Acquisition, 22, 69-84.

Benati, A. (2001). A Comparative study of the effects of processing instruction and output- based instruction on the acquisition of the Italian future tense. Language Teaching Research, 5(2), 95-127. http://dx.doi.org/10.1177/136216880100500202 
Benati, A. (2005). The effects of processing instruction, traditional instruction and meaning- output instruction on the acquisition of the English past simple tense. Language Teaching Research, 9(1), 67-93. http://dx.doi.org/10.1191/13621688051r154oa

Buck, M. (2006). The effects of processing instruction on the acquisition of English progressive aspect. Estudios de Lingüística Aplicada, 24(43), 77-95.

Cadierno, T. (1995). Formal instruction from a processing prospective: an investigation into the Spanish past tense. Modern Language Journal, 79(2), 179-93. http://dx.doi.org/10.1111/j.1540-4781.1995.tb05430.x

Celce-Murcia, M. (1991). Grammar pedagogy in second and foreign language teaching. TESOL Quarterly, 25(3), 459-480. http://dx.doi.org/10.2307/3586980

Ellis, R. (2001). Form-focused instruction and second language learning. Malden, MA: Blackwell.

Erlam, R. (2003). Evaluating the relative effectiveness of structured input and output- based instruction in foreign language learning. Studies in Second Language Acquisition, 25, 559-582. http://dx.doi.org/10.1017/S027226310300024X

Farley, A. (2001). Authentic processing instruction and the Spanish subjunctive. Hispania, 84, $289-299$. http://dx.doi.org/10.2307/3657760

Hinkel, E. (2002). Teaching grammar in writing classes: Tenses and cohesion. In E. Hinkel, \& S. Fotos (Eds.), New perspectives on grammar teaching in second language classrooms (pp. 181-198). Mahwah, NJ: Lawrence Erlbaum Associates.

Morgan- Short, K., \& Bowden, H. W. (2006). Processing instruction and meaningful output- based instruction. Studies in Second Language Acquisition, 28, 31-65.

Norris, J. M., \& Ortega, L. (2000). Effectiveness of L2 instruction: A research synthesis and quantitative meta-analysis. Language Learning, 50(3), 417-528. http://dx.doi.org/10.1111/0023-8333.00136

Qin, J. (2008). The effect of processing instruction and dictogloss tasks on acquisition of the English passive voice. Language Teaching Research, 12, 61-82. http://dx.doi.org/10.1177/1362168807084494

Saraceni, M. (2008). Meaningful form: Transitivity and intentionality. ELT Journal, 53(3), 164-172.

Sharwood Smith, M. (1993). Input enhancement in instructed SLA: Theoretical bases. Studies in Second Language Acquisition, 15, 165-179. http://dx.doi.org/10.1017/S0272263100011943

VanPatten, B. (1993). Grammar instruction for the acquisition rich classroom. Foreign Language Annals, 26, 433-450.

VanPatten, B. (1996). Input processing and grammar instruction in second language acquisition. Norwood, NJ: Ablex.

VanPatten, B. (2000). Processing instruction as form-meaning connections: Issues in theory and research. In J. Lee, \& A. Valdman (Eds.), Form and meaning: Multiple perspectives (pp. 43-68). Boston: Heinle \& Heinle.

VanPatten, B. (2002a). Processing instruction: An update. Language Learning, 52, 755-803.

VanPatten, B. (2002b). Processing the content of input processing and processing instruction research: A response to DeKeyser, Salaberry, Robinson and Harrington. Language Learning, 52, 825-831. http://dx.doi.org/10.1111/1467-9922.00203

VanPatten, B. (2003). From input to output: A teacher's guide to second language acquisition. Boston: McGraw Hill.

VanPatten, B. (2004a). Processing instruction: Theory, research and commentary. NJ: Lawrence Erlbaum Associates.

VanPatten, B. (2004b). Several reflections on why there is good reason to continue researching the effects of processing instruction. In B. VanPatten, (Ed), Processing instruction: Theory, Research and Commentary (pp. 325-335). Mahwah, NJ: Lawrence Erlbaum Associates.

VanPatten, B., \& Cadierno, T. (1993). Input processing and second language acquisition: A role for instruction. Modern Language Journal, 77, 45-57. http://dx.doi.org/10.1111/j.1540-4781.1993.tb01944.x

VanPatten, B., \& Wong, W. (2004). Processing instruction and the French causative: a replication. In B. VanPatten (Ed.), Processing instruction: Theory, research and commentary (pp. 97-118). Mahwah, NJ: Erlbaum. 
Wong, W., \& VanPatten, B. (2003). The evidence is IN: Drills are out. Foreign Language Annals, 36(3), 403-423. http://dx.doi.org/10.1111/j.1944-9720.2003.tb02123.x

Wong, W. (2004). Processing instruction in French: The roles of explicit information and structured input. In B. VanPatten (Ed.), Processing instruction: Theory, research and commentary (pp. 187-205). Mahwah, NJ: Erlbaum. 